\title{
Price knowledge and search behavior for habitual, low involvement food purchases *
}

\author{
Jouni T. Kujala ${ }^{a}$ and Michael D. Johnson ${ }^{b}$ \\ ${ }^{a}$ University of Helsinki, Helsinki, Finland \\ ${ }^{b}$ University of Michigan, Ann Arbor, USA
}

Received January 27, 1992; accepted February 16, 1993

\begin{abstract}
Existing models of price search presume a direct link between knowledge and search behavior. We argue that these models are not well suited to more habitual, low involvement purchase situations where search behavior and price knowledge are more independent. An alternative, adaptive rationality model is proposed in which these constructs are only indirectly related. An empirical study of Finnish consumers' purchascs of fresh produce and meat products is reported which supports the adaptive rationality model.
\end{abstract}

\section{Introduction}

Research on the economics of information presumes that consumers search for price information until the marginal cost of search exceeds the marginal benefit (Stigler 1961). The end-result of this search process is an acquired level of knowledge regarding the prices at which different goods are normally available. In contrast, consumer researchers view knowledge as having an important effect on search (Bettman 1986; Jacoby et al. 1978; Moore and Lehmann 1980; Punj and Staelin 1983). Specifically, consumers may have a concrete knowledge of available price levels which allows them to limit their prepurchase search behavior (Urbany 1986).

Both approaches presume a direct relationship between price knowledge and search behavior. As described below, these models

Correspondence to: M.D. Johnson, University of Michigan, School of Business Administration, Ann Arbor, MI 48109-1234, USA.

* The authors thank Genc Anderson, Rick Bagozzi, Claes Fornell, and two anonymous reviewers for their valuable comments on the research. 
may be very applicable to major or high involvement purchases. Yet they may not describe more habitual, low involvement purchases where there may be no direct or obvious connection between search behavior and acquired price knowledge (Reynaud 1981). Instead, learning may be more adaptive (March 1978) or incidental (Mazumdar and Monroe 1990) in nature.

The goal of this paper is to examine the determinants of price knowledge and search behavior for habitually purchased food products. An empirical study of Finnish consumers' purchases of fresh produce and meat products is reported which supports an adaptive rationality model of price knowledge and search behavior.

\section{Search behavior and price knowledge}

Three factors are central to our discussion, price importance, price knowledge, and search behavior. Price importance captures differences across consumers with regard to their inherent sensitivity to price for a given product or product category. From a cost-benefit standpoint, the more important price is to any given consumer the more likely that consumer is to follow available price information. As described below, just how consumers follow price information should depend on the type of choice involved.

Price knowledge, in this context, is the consumer's perceived knowledge, or uncertainty (Urbany 1986), regarding the prices at which different goods are normally available. Consumers' own perceptions of price knowledge are critically important here, particularly as they relate to search behavior. Although subjective perceptions may not be valid measures of actual or stored knowledge (Brucks 1985), they are closely linked to a consumer's self-confidence and often provide a better understanding of information processing strategies and tactics than do more objective knowledge measures (Park and Lessig 1981; Kuusela 1992).

Finally, search behavior is defined as the number of stores searched prior to purchase. As well as having obvious retail significance, this definition is also very consistent with earlier operationalizations of price search (Carlson and Gieseke 1983; Urbany 1986). More generally, it is consistent with the prevailing consumer research view of 
search as the degree to which consumers gather information from their purchase environment prior to making a choice (Bettman 1986).

Early economic models presumed that consumers had complete knowledge of the products and prices available in a market. Stigler's (1961) economics of information or EOI model was the first to relax this 'perfect knowledge' assumption. Stigler developed the EOI model to explain the ascertainment of price knowledge in a market. $\mathrm{He}$ proposed that consumers gain this price knowledge via search behavior. Consumers search for price so long as the marginal returns from search exceed the marginal costs. Conceptually, cost-benefit considerations drive search behavior of which price knowledge is an end-product. Empirical support for the EOI model has been mixed (for reviews see Johnson and Puto 1987; and Urbany 1986). This stems, in part, from the model's restrictive assumption regarding knowledge. The EOI model presumes that consumers enter a market possessing only an abstract level of price knowledge. That is, they know the relative dispersion of prices in a market but do not know which sellers offer which prices.

Challenging this presumption, Urbany (1986) argued that consumers may have a concrete knowledge of price levels for major purchases. Through experience, many consumers know which retailers are likely to have lower or higher prices which limits their search behavior. This prediction is consistent with other studies involving durable products which show a general reduction in external information search with prior knowledge or experience (Katona and Mueller 1955; Newman and Staelin 1971, 1972; Punj and Staelin 1983).

Using a computer shopping procedure and consumer durables (clothes dryers) as stimuli, Urbany had consumers gather price information from different retail outlets while manipulating price knowledge (uncertainty), price dispersion, and search costs. Under certain conditions, the high knowledge (low uncertainty) subjects searched fewer stores than did the low knowledge (high uncertainty) subjects. This suggests an alternative model, referred to here as the low uncertainty or LU model, where increased price knowledge has a direct negative effect on search behavior.

The important theoretical difference between these models regarding the dynamics of price knowledge and search behavior is illustrated in Figure 1. While Stigler's original EOI model is a static model, it is very clearly based on dynamic arguments regarding the nature of 


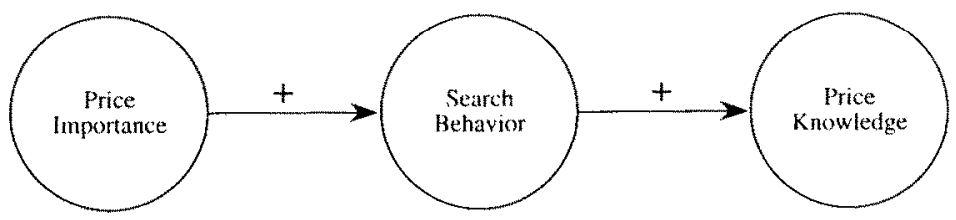

Ecomomics of Information Model

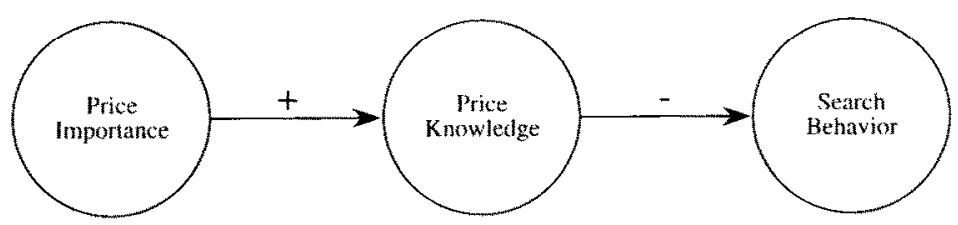

Low Uncertainty Model

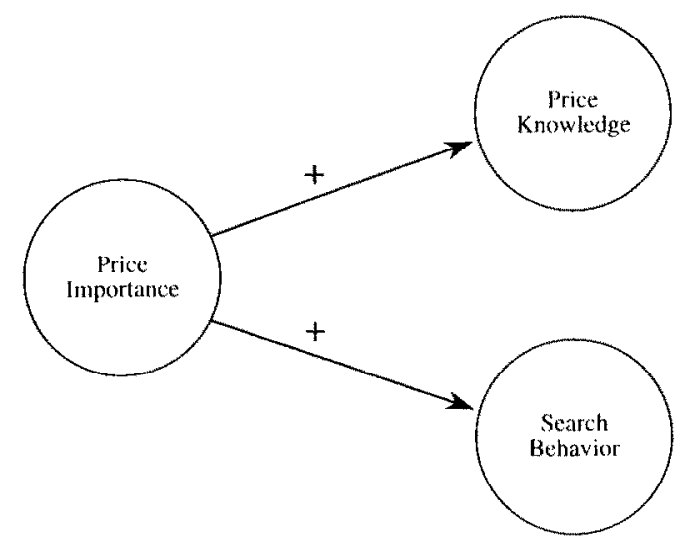

Adaptive Rationality Model

Fig. 1. Three models of price importance, price knowledge, and search behavior.

search. Accordingly, consumers who value price information from a cost-benefit standpoint should engage in an overt, external search process. As a result of this search behavior, consumers increase their price knowledge or 'ascertain the most favorable price' (Stigler 1961: 213). Therefore, price importance should positively affect search behavior which, in turn, should positively affect price knowledge.

Under the LU model there should be a more direct link from price importance to price knowledge. Here consumers have some accumulated experience of past purchases on which they can draw to ascer- 
tain price information. The degree to which they actually use this information to build a concrete knowledge of expected price differences should depend on the importance they place on price. Consumers who value price information are more likely to have attended to and processed past price information and the knowledge they acquire subsequently serves to limit their search behavior. In Figure 1, price importance should increase price knowledge which, in turn, should decrease or limit search.

The EOI and LU models describe very different purchase situations. The EOI model was designed with unique purchases in mind where consumers are likely to have a restricted knowledge of possible prices. This may include the purchase of a new home or automobile. Other major purchases, such as home appliances (e.g., washers and dryers) or entertainment devices (e.g., televisions and VCRs), are typically made through appliance or department stores. These retailers vary predictably in their price levels across categories. Consistent with the LU model, consumers should use this knowledge to limit their search behavior. Unfortunately, neither of these conceptualizations seems appropriate for more habitual, low involvement purchases.

\section{Price knowledge and search behavior for habitual, low involvement purchases}

Both the EOI and LU models describe relatively infrequent, high involvement purchase situations in which an overt spending decision and resulting search process is likely. In contrast, consumers purchase relatively inexpensive, frequently purchased nondurables in a more habitual, low involvement fashion (Howard 1977; Katona 1975, 1981). In particular, food purchase decisions are often made quickly with little overt processing of information at the point of purchase (Hoyer 1984; Russo et al. 1986). This suggests that an overt cognitive process linking price knowledge and search behavior is unlikely.

Yet the predominant approach has been to presume such a link. For example, Jacoby et al. (1978) hypothesized that nondurables, like durables, should show a decrease in pre-purchase information search with prior knowledge. Interestingly, their results revealed a positive rather than negative relationship. Moore and Lehmann (1980) did 
show a decrease in search behavior with knowledge/experience in a longitudinal study of bread choice. However, their study involved five alternatives of an unfamiliar brand and thus may be atypical of most habitual, low involvement purchases.

March (1978; see also Cyert and March 1963) describes an alternative type of adaptive rationality (AR) model that may more accurately describe the learning of price information for routine purchases. Adaptive rationality 'is a form of intelligence that tends to separate current reasons from current actions' (March 1978: 593). Instead, AR type models emphasize experimental learning over time periods or, in this case, purchase occasions (Blomqvist 1983; Johnson and Plott 1989; Lovell 1986; Nerlove 1958). A classic example is Nerlove's (1958) adaptive expectations model where all past period prices contribute to price expectations. This is very similar to the type of learning described under the LU model. The more important price is to any given consumer, the more likely price information is processed and used to update price knowledge from purchase to purchase. Any observed differences in price knowledge should be a direct function of the importance consumers place on price. However, in contrast to both the LU and EOI models, price knowledge should be independent of search. Price knowledge is neither acquired from an overt search process or used to limit search prior to any given purchase. Instead, it is derived from actual prices paid across purchase occasions.

This is similar to Mazumdar and Monroe's (1990) notion of 'incidental' learning. In contrast to 'intentional' learning, incidental learning occurs when learning is not the consumer's primary goal. Rather, learning is a by-product of some other activity such as purchase or consumption. One result of this type of learning is that memory for price information is superior for chosen brands.

Adaptive rationality does not imply the absence of search behavior for habitual, low involvement purchases. This is particularly true of fresh food products that are subject to seasonal and supply related variations in price and quality. Some level of uncertainty and resulting search should exist independent of consumers' price knowledge. Thus we predict that, for habitually purchased products, price importance should have some positive effect on search behavior across consumers. Most likely this relationship reflects price sensitive consumers who reject a price that they consider to be too high (Emery 1970; Kalwani et al. 1990). As a result, they visit more stores on average than 
consumers who are less price sensitive. Importantly, this search behavior is a reaction to an inherent, purchase to purchase variation in price. Under adaptive rationality, pre-purchase search behavior does not play an integral role in the development of price knowledge.

Figure 1 presents an AR model for low involvement food purchase decisions which incorporates these features. According to the model, price sensitive consumers are more likely to follow and process price information across purchase occasions thereby increasing their price knowledge. Although price sensitive consumers may engage in some search behavior prior to purchase (e.g., reject a high price), this search does not mediate their acquired price knowledge. In contrast, both the EOI and LU models predict some direct relationship between search behavior and price knowledge. There are conditions under which the EOI model predicts little or no relationship between price search and price knowledge. Due to diminishing returns, this relationship should approach zero as the absolute number of searches increases. However, consistent with the conceptualization in Figure 1, search behavior is the only antecedent of price knowledge under this model. We now report on an empirical study that examines the ability of the three models to describe consumer food purchase behavior.

\section{Empirical study}

\section{Method}

The data used in the study is from a larger mail survey of Finnish consumers' purchases of fresh foodstuffs (Kujala 1989, 1992). It includes two independent surveys collected in late 1987, one regarding purchases of fresh produce (i.e., fruits and vegetables) and one regarding purchases of fresh meat. These product groups were chosen because they form distinct and important categories for both consumers and retailers (Terävä 1990). These products are purchased quite regularly because of their freshness requirements and their central role in a healthy diet. The nature of the buying is therefore repetitious and quite routine. Both surveys were based on a random sample of 18-80 year old people living in cities with over 15,000 inhabitants. The sample size was 1,726 for produce and 1,608 for meat and the response rate in both cases was 48 percent. 
The Kujala (1989) study suggests that the behavior of men and women may be quite different in these purchase decisions. This is consistent with other consumer research studies showing systematic differences in perceptions and behavior between males and females (e.g., DeSarbo et al. 1992; Gentry et al. 1978; Meyers-Levy 1988). Therefore, the responses of women and men are treated separately.

Two selection criteria were used to focus on particular respondents. First, we only examined those individuals who indicated that they handle or at least equally share the household food purchase duties. This helps eliminate individuals for whom food purchases are not relatively habitual. Second, we excluded those consumers with special dietary restrictions who may be more involved with such purchases than is a typical food buyer. These selection criteria resulted in 864 female produce buyers, 366 male produce buyers, 838 female meat buyers, and 350 male meat buyers. Each questionnaire focused on the specific context of buying either fresh meat or fresh produce. Overall, the questionnaires included approximately 70 measures or questions regarding product usage, quality, price, healthiness, buying habits, choice factors, social influences, advertising, and demographics (see Kujala 1992).

\section{Measures}

Five measures were used to operationalize the three different constructs in Figure 1. Price importance captures the importance of price as a decision making factor and is measured reflectively by three questions. The first question measured a person's own perceived importance of price $\left(I_{1}\right)$. Translated from Finnish, the question asked 'How important is the price you notice in a store for your choice?' Responses were on a 5-point scale ranging from 'not very important' (1) to 'very important' (5). The second item $\left(I_{2}\right)$ measured price importance via a person's sensitivity to price offers or promotions (Blattberg et al. 1978). The question asked 'How often do you choose the item on the basis of a price offer while shopping?' Responses were on a 5-point scale ranging from 'very seldom' (1) to 'very often' (5). Finally, the degree to which a consumer attends to or 'follows' prices should also reflect price importance. The third price importance question $\left(\mathrm{I}_{3}\right)$ therefore asked 'How much do you follow the prices of fruit and vegetables (fresh meat) while buying?' Responses were again 
on a 5-point scale ranging from 'nearly not at all' (1) to 'nearly always' (5).

The price knowledge and search constructs were each measured using single indicators, $\mathrm{K}_{1}$ and $\mathrm{S}_{1}$. For price knowledge $\left(\mathrm{K}_{1}\right)$ consumers were asked 'While buying fruit and vegetables (fresh meat) how well do you suppose that you know the normal prices of those products?' on a 5-point scale anchored by the following statements: 'hard to know' (1), 'quite difficult to know' (2), 'know the prices of some products but not many' (3), 'know the price level of quite many' (4), and 'easy to know most of the normal prices' (5). This measure is consistent with our definition of price knowledge as consumers' own perception of their knowledge or uncertainty regarding price (Kuusela 1992).

For the search behavior construct $\left(S_{1}\right)$, consumers were asked 'How many different stores do you normally visit during one week for the purchase of fresh fruits and vegetables (fresh meat)?' The 5-point scale used here ranged from 'one store' (1) to 'five stores' (5). While other exogenous variables likely influence this measure (e.g., retail density), it is consistent with both our definition of price search and previous research on search behavior (e.g., Carlson and Gieseke 1983; Urbany 1986).

\section{Causal model estimation}

The fundamental differences among the models in Figure 1 involve the causal relationships among the three constructs. Price importance is also a latent construct measured reflectively by three separate indicators. It is important, therefore, that the competing models be estimated via appropriate causal modeling procedures. Two recommended methods are partial least squares or PLS (Wold 1982) and covariance structure analysis via LISREL7 (Jöreskog and Sörbom 1989a).

However, LISREL and PIS have particular objectives and may provide different results. In the present application, PLS aims to account for variances at the observed (i.e., measurement) level while LISREL aims to account for observed covariances. This difference increases the potential for results that are an artifact of the estimation method (Fornell and Bookstein 1982). Given the central importance of causal relationships in distinguishing among the models in Figure 1, 
both methods were used here to estimate and compare all three models. As our measures are relatively ordinal (given the categorical labels used to collect responses) we used polychoric correlations as input to both the LISREL and PLS analyses (Jöreskog and Sörbom 1989b). We also used the weighted least square (WL) option in LISREL to provide asymptotically distribution-free parameter estimates. The asymptotic variance/covariance matrices needed for these WL-estimations were obtained through the PRELIS program (Jöreskog and Sörbom 1989b).

\section{PLS analysis and results}

A total of 12 PLS models were estimated, one for each of the three models for each of the four data sets (women buying produce, men buying produce, women buying meat, and men buying meat). The loadings for the three indicators of price importance were large and positive for each estimated model. Across the models, the loadings ranged from a low of 0.84 to a high of 0.95 and averaged $0.89,0.86$, and 0.93 for $I_{1}, I_{2}$, and $I_{3}$ respectively.

The estimated path coefficients are presented in Table 1 . These coefficients are lowest for the EOI model, averaging 0.25 for the effect of price importance on search and 0.12 for the subsequent effect of search on price knowledge. The coefficients for the LU model are larger due to the effect that price importance had on price knowledge (mean of 0.41 ). However, the LU model predicts a negative relationship from price knowledge to search. With the exception of a very small negative effect for men's shopping for meat, the effect was generally positive (mean of 0.12 ).

The largest coefficients were found for the AR model where, on average, the effects of price importance on price knowledge and search behavior were 0.40 and 0.25 respectively. In all four AR model estimations the coefficients were in the predicted direction. An important feature of the AR model is that any observed covariation between price knowledge and price search is not direct but rather due to their having price importance as a common antecedent. Consistent with this argument, the residual covariance between the price knowledge and search behavior constructs for the AR model was very small in each case, equalling $0.03,0.04,0.05$, and 0.06 respectively for the Women/ Produce, Men/Produce, Women/Meat, and Men/Meat models. In 
Table 1

Path coefficients and goodness-of-fit measure estimated by PLS for the EOI (economics of information), LU (low uncertainty), and AR (adaptive rationality) models.

\begin{tabular}{llll}
\hline Sample & EOI model & LU model & AR model \\
\hline Women buying produce & & & \\
PI to SB & 0.269 & - & 0.264 \\
SB to PK & 0.135 & - & - \\
PI to PK & - & 0.414 & 0.412 \\
PK to SB & - & 0.135 & - \\
RMR & 0.220 & 0.128 & 0.015 \\
Men buying produce & & - & 0.358 \\
PI to SB & 0.358 & - & - \\
SB to PK & 0.198 & 0.446 & 0.439 \\
PI to PK & - & 0.198 & - \\
PK to SB & - & 0.170 & 0.023 \\
RMR & 0.219 & - & \\
Women buying meat & & - & 0.270 \\
PI to SB & 0.268 & 0.394 & - \\
SB to PK & 0.159 & 0.159 & 0.391 \\
PI to PK & - & 0.129 & - \\
PK to SB & - & & 0.031 \\
RMR & 0.204 & - & 0.104 \\
Men buying meat & & - & - \\
PI to SB & 0.114 & 0.367 & 0.363 \\
SB to PK & -0.024 & -0.024 & - \\
PI to PK & - & 0.069 & 0.036 \\
PK to SB & - & 0.184 & \\
RMR & & & \\
\hline
\end{tabular}

Note: $\mathrm{PI}=$ price importance, $\mathrm{SB}=$ search behavior, $\mathrm{PK}=$ price knowledge, and $\mathrm{RMR}=$ root mean squared residual.

contrast, the residual covariance between price importance and price knowledge for the EOI model equalled 0.37, 0.36, 0.34, and 0.32 across the four data sets. The corresponding residuals between price importance and price search for the LU model were $0.21,0.26,0.21$, and 0.11. This suggests that the AR model offers a more appropriate specification of the causal relations among the three constructs for these data sets.

The goodness-of-fit of the models, as measured by the root mean squared residual for the latent variables in each model (RMR in Table 1), also supports this conclusion. On average, RMR is greater for the EOI model than for the LU model averaging 0.21 and 0.12 respectively. However, three of the four coefficients involving price 
knowledge and search behavior for the LU model were not in the predicted direction. RMR was lowest for the AR model averaging 0.03 and all of the coefficients were in the predicted direction. Overall the PLS analyses suggest that the AR model does a better job of explaining these data.

\section{LISREL analysis and results}

A total of 12 LISREL models were also estimated. Four prominent overall fit measures are used here: chi-square test, goodness-of-fit index (GFI), adjusted goodness-of-fit index (AGFI), and root mean squared residual (RMR). Following Bagozzi and Yi (1988), recommended levels of acceptable fit for a model are a $p$-value of chi-square test over 0.05 , GFI and AGFI values over 0.9 and very small RMR values $(<0.05)$. Unlike the GFI, AGFI and RMR measures, the chi-square statistic is a direct function of sample size (Bentler and Bonett 1980). The probability of rejecting any model increases as sample size increases, even when the model is minimally false. Therefore, as our female samples are much larger than our male samples, the chi-square statistic is a conservative test for the models describing women's behavior.

The factor (measurement) loadings for price importance were large and positive for each estimated model. The loadings ranged from 0.76 to 0.91 and averaged $0.84,0.78$, and 0.89 for $I_{1}, I_{2}$, and $I_{3}$ respectively. The error variances for these loadings ranged from 0.17 to 0.42 and averaged $0.30,0.39$, and 0.21 for $I_{1}, I_{2}$, and $I_{3}$. The average composite reliability for price importance was 0.87 , which is quite high.

The path coefficients and gondness of fit values are presented in Table 2. As the emphasis in LISREL is on the explanation of covariances, we must first look at the overall fit measures before interpreting the path coefficients. Both the EOI and LU models had unacceptable levels of fit according to the chi-square test and RMR values for all four data sets. AGFI is also below acceptable levels for the EOI model in three of four cases. The AR model had acceptable levels of GFI, AGFI, and RMR for all four data sets. The chi-squares were also acceptable for the male produce and meat buying dala. Only for the female produce and female meat buying data were the chi-squares unacceptable and, as mentioned, this is a conservative fit measure for these samples. Chi-square difference tests show that in 
Table 2

Path coefficients and goodness-of-fit measures estimated by LISREL7 for the EOI (economics of information), LU (low uncertainty), and AR (adaptive rationality) models.

\begin{tabular}{|c|c|c|c|}
\hline Sample & EOI model & LU model & AR model \\
\hline \multicolumn{4}{|c|}{ Women buying produce } \\
\hline $\mathrm{PI}$ to $\mathrm{SB}$ & 0.493 & - & 0.279 \\
\hline SB to $\mathrm{PK}$ & 0.503 & - & - \\
\hline PI to PK & - & 0.489 & 0.438 \\
\hline PK to $\mathrm{SB}$ & - & 0.305 & - \\
\hline$x^{2}$ & 210.3 & 63.4 & 14.9 \\
\hline$p$-value & 0.000 & 0.000 & 0.011 \\
\hline GFI & 0.959 & 0.988 & 0.997 \\
\hline AGFI & 0.877 & 0.963 & 0.991 \\
\hline RMR & 0.118 & 0.072 & 0.032 \\
\hline \multicolumn{4}{|c|}{ Men buying produce } \\
\hline PI to SB & 0.601 & - & 0.384 \\
\hline $\mathrm{SB}$ to $\mathrm{PK}$ & 0.562 & - & - \\
\hline PI to PK & - & 0.578 & 0.474 \\
\hline PK to SB & - & 0.428 & - \\
\hline$x^{2}$ & 75.0 & 41.2 & 7.8 \\
\hline$p$-value & 0.000 & 0.000 & 0.165 \\
\hline GFI & 0.967 & 0.982 & 0.997 \\
\hline AGFI & 0.900 & 0.945 & 0.990 \\
\hline RMR & 0.098 & 0.082 & 0.033 \\
\hline \multicolumn{4}{|c|}{ Women buying meat } \\
\hline $\mathrm{PI}$ to $\mathrm{SB}$ & 0.461 & - & 0.290 \\
\hline SB to $\mathrm{PK}$ & 0.464 & - & - \\
\hline PI to PK & - & 0.469 & 0.416 \\
\hline PK to SB & - & 0.310 & - \\
\hline$x^{2}$ & 177.7 & 67.6 & 21.5 \\
\hline$p$-value & 0.000 & 0.000 & 0.001 \\
\hline GFI & 0.962 & 0.985 & 0.995 \\
\hline AGFI & 0.885 & 0.956 & 0.986 \\
\hline RMR & 0.112 & 0.075 & 0.039 \\
\hline \multicolumn{4}{|c|}{ Men buying meat } \\
\hline PI to SB & 0.170 & - & 0.104 \\
\hline SB to $\mathrm{PK}$ & 0.128 & - & - \\
\hline PI to PK & - & 0.381 & 0.373 \\
\hline PK to SB & - & 0.053 & - \\
\hline$x^{2}$ & 106.3 & 16.4 & 10.5 \\
\hline$p$-value & 0.000 & 0.006 & 0.063 \\
\hline GFI & 0.948 & 0.992 & 0.995 \\
\hline AGFI & 0.845 & 0.976 & 0.985 \\
\hline RMR & 0.141 & 0.057 & 0.043 \\
\hline
\end{tabular}

Note: $\mathrm{PI}=$ price importance, $\mathrm{SB}=$ search behavior, $\mathrm{PK}=$ price knowledge, $\mathrm{GFI}=$ goodness-of-fit index, $\mathrm{AGFI}=$ adjusted goodness-of-fit index, and RMR = root mean squared residual. 
both of these cases the AR model fits significantly better than the other two models.

The overall poor fit of the EOI and LU models makes any interpretation of path coefficients problematic. The AR model offers more meaningful estimates. Note the similarity of the LISREL path coefficients for this model to those obtained using PLS. The average effect of price importance on price knowledge is 0.43 for LISREL versus 0.40 for PLS. The average effect of price importance on search behavior is 0.26 for LISREL versus 0.25 for PLS. The marginally greater coefficients in the LISREL output is consistent with the difference in fitting objectives.

We further explored the equality of the AR model structure across our four data sets using the multi-sample analysis available in LISREL7. First we examined whether the factor loadings are invariant for: (a) women and men buying produce, (b) women and men buying fresh meat, (c) women buying produce and meat, and (d) men buying produce and meat. The chi-square difference tests were insignificant in all four cases supporting equal factor loadings across the samples. As the factor loadings are equivalent, we can then examine whether there is similar invariance in the AR model path coefficients. Chisquare difference tests show significant differences between men and women purchasing meat $\left(\chi^{2}\right.$ difference $\left.=17.42, d f=2, p<0.01\right)$ and produce $\left(\chi^{2}\right.$ difference $\left.=6.26, d f=2, p<0.05\right)$. Although these differences are not systematic, they are in accordance with our assumption regarding perceptual differences between men and women. There was no difference in the structure of women's purchase behavior of produce and meat while men's behavior was quite different between these categories $\left(\chi^{2}\right.$ difference $=29.99, d f=2, p<0.01$ ). Basically men do not search much at all for meat suggesting that they are satisfied with the store they currently shop.

\section{Summary and discussion}

Our study examined the ability of three different models of price knowledge and search behavior to explain Finnish consumers' purchases of fresh produce and meat products. Overall the results are more consistent with a proposed adaptive rationality model than with two existing models, an economics of information model and a low 
uncertainty model. Accordingly, consumers who place greater importance on price both acquire a greater knowledge of price information across purchase occasions and are more likely to engage in search behavior. Yet price knowledge and search behavior are not directly related. Rather, they each have price importance as a common antecedent. Thus previous support for a knowledge-search relationship in the context of nondurables may be misleading.

The primary implication of our study is that the learning of price information for nondurables is relatively adaptive or incidental in nature. Consumers learn and form expectations regarding price levels across purchase occasions, not in the context of a particular choice. Thus existing models of price search, developed in more high involvement contexts, fail to describe a large segment of consumer purchases. Consistent with Urbany's (1986) study, consumers appear unlikely to engage in search when price information is readily accessible in memory. As Urbany concludes, search is a complex process and no one model likely provides universally appropriate predictions. A practical implication of the study is that consumer demand for habitual, low involvement products should be relatively price inelastic on any given purchase occasion. Consumers are relatively unlikely to search different stores to locate a lower price. At the same time consumers are adaptive and, when motivated, they learn where to expect lower prices.

A possible limitation of our study is that we focus on fresh foodstuffs where few if any brand names exist. However, our consumers represented a wide range of age groups and were responding to actual purchase decisions which increases the external validity of our findings. Methodologically our study may be limited in that our price knowledge and search behavior constructs were measured using single indicators. Yet in each case the measure followed directly from our definition of the construct. Finally, all of our measures were obtained using the same research method. It will be important to replicate our findings in different populations using alternative measures and methods.

\section{References}

Bagozzi, R.P. and Y. Yi, 1988. On the evaluation of structural equation models. Journal of the Academy of Marketing Science 16, 74-94. 
Bentler, P.M. and D.G. Bonett, 1980. Significance tests and goodness of fit in the analysis of covariance structures. Psychological Bulletin 88, 588-606.

Bettman, J.R., 1986. Consumer psychology. Annual Review of Psychology 37, 257-289.

Blattberg, R.C., T. Buesing, P. Peacock and S. Sen, 1978. Identifying the deal prone consumer. Journal of Marketing Research 15, 369-377.

Blomqvist, H.C., 1983. On the formation of inflationary expectations: Some empirical evidence from Finland, 1979-1980. Journal of Economic Psychology 4, 319-334.

Brucks, M., 1985. The effects of product class knowledge on information search behavior. Journal of Consumer Research 12, 1-16.

Carlson, J.A. and R.J. Gieseke, 1983. Price search in a product market. Journal of Consumer Research 9, 357-365.

Cyert, R.M. and J.G. March, 1963. A Behavioral Theory of the Firm. Englewood Cliffs, NJ: Prentice-Hall.

DeSarbo, W.S., M.D. Johnson, A. Manrai, L. Manrai and E.A. Edwards, 1992. TSCALE: A new multidimensional scaling procedure based on Tversky's contrast model. Psychometrika 57, 43-69.

Emery, F., 1970. 'Some psychological aspects of price'. In: B. Taylor and G. Wills (Eds.), Pricing strategy (pp. 98-111). Princeton, NJ: Brandon/Systems Press.

Fornell, C. and F.L. Bookstein, 1982. Two structural equation models: LISREL and PLS applied to consumer exit-voice theory. Journal of Marketing Research 19, 440-452.

Gentry, J.W., M. Doering and T.V. O'Brien, 1978. 'Masculinity and femininity factors in product perception and self image’. In: H.K. Hunt (Ed.), Advances in Consumer Research, Vol. 5 (pp. 326-332). Ann Arbor, MI: Association for Consumer Research.

Howard, J., 1977. Consumer Behavior: Application of Theory. New York: McGraw-Hill.

Hoyer, W.D., 1984. An examination of consumer decision making for a common repeat purchase product. Journal of Consumer Research 11, 822-829.

Jacoby, J., R.W. Chestnut and W.A. Fisher, 1978. A behavioral process approach to information acquisition in nondurable purchasing. Journal of Marketing Research 15, 532-544.

Johnson, M.D. and C. Plott, 1989. The effect of two trading institutions on price expectations and the stability of supply-response lag markets. Journal of Economic Psychology 10, $189-216$.

Johnson, M.D. and C.P. Puto, 1987. 'A review of consumer judgment and choice'. In: M.J. Houston (Ed.), Review of Marketing 1987 (pp. 236-292). Chicago, IL: American Marketing Association.

Jöreskog, K.G. and D. Sörbom, 1989a. LISREL7: A Guide to the Program and Applications. Chicago, IL: SPSS Inc.

Jöreskog, K.G. and D. Sörbom, 1989b. SPSS LISREL7 and PRELIS User's Guide and Reference. Chicago, IL: SPSS Inc.

Kalwani, M.U., C.K. Yim, H.J. Rinne and Y. Sugita, 1990. A price expectations model of customer brand choice. Journal of Marketing Research 27, 251-262.

Katona, G., 1975. Psychological Economics. New York: Elsevier.

Katona, G., 1981. Essays on behavioral economics. Ann Arbor, MI: The University of Michigan, Institute for Social Research.

Katona, G. and E. Mueller, 1955. 'A study of purchase decisions'. In: L.H. Clark (Ed.), Consumer Behavior: The Dynamics of Consumer Reaction (pp. 30-87). New York: New York University Press.

Kujala, J., 1989. Hedelmien ja vihannesten ostopäätökseen vaikuttavat tekijät [Factors affecting the buying of fruit and vegetables]. Licentiate work, EKT-Series 784. University of Helsinki, Dept. of Economics and Management. Helsinki, Finland.

Kujala, J., 1992. Purchasing fresh foodstuffs: An example of repetitive choice behavior (disserta- 
tion). EKT-Series 888. University of Helsinki, Dept. of Economics and Management. Helsinki, Finland.

Kuusela, A., 1992. The effects of actual and self-perceived knowledge on the use of elementary information processes (EIPs) in a choice task. Acta Universitatis Tamperensis, Series A, Vol. 333. University of Tampere, Finland.

Lovell, M.C., 1986. Tests of the rational expectations hypothesis. American Economic Review 76, $110-124$.

March, J.G., 1978. Bounded rationality, ambiguity, and the engineering of choice. Bell Journal of Economics 9, 587-608.

Mazumdar, T. and K.B. Monroe, 1990. The effects of buyers' intentions to learn price information on price encoding. Journal of Retailing 66, 15-32.

Meyers-Levy, J., 1988. The influence of sex roles on judgment. Journal of Consumer Research $14,522-530$.

Moore, W.L. and D.R. Lehmann, 1980. Individual differences in search behavior for a nondurable. Journal of Consumer Research 7, 296-307.

Nerlove, M., 1958. Adaptive expectations and cobweb phenomena. Quarterly Journal of Economics $73,227-240$.

Newman, J.W. and R. Staelin, 1971. Multivariate analysis of differences in buyer decision time. Journal of Marketing Research 8, 192-198.

Newman, J.W. and R. Staelin, 1972. Prepurchase information seeking for new cars and major household appliances. Journal of Marketing Research 9, 249-257.

Park, C.W. and V.P. Lessig, 1981. Familiarity and its impact on consumer decision biases and heuristics. Journal of Consumer Research 8, 223-230.

Punj, G.N. and R. Staelin, 1983. A model of consumer information search behavior for new automobiles. Journal of Consumer Research 9, 366-380.

Reynaud, P.-L., 1981. Economic Psychology. New York: Praeger.

Russo, J.E., R. Staelin, C.A. Nolan, G.J. Russell and B.L. Metcalf, 1986. Nutrition information in the supermarket. Journal of Consumer Research 13, 48-70.

Stigler, G.J., 1961. The economics of information. Journal of Political Economy 69, 213-225.

Terävä, T., 1990. Tuotto paremmaksi lihavalmistekaupassa. Myyntineuvoja 1-90, 26-30.

Urbany, J.E., 1986. An experimental examination of the economics of information. Journal of Consumer Research 13, 257-271.

Wold, H., 1982. 'Systems under indirect observation using PLS'. In: C. Fornell (Ed.), A Second Generation of Multivariate Analysis: Methods (pp. 325-347). New York: Praeger. 